\title{
FIBER REINFORCED POLYMER REINFORCEMENT FOR CONSTRUCTION- STATE OF THE ART REVIEW
}

\author{
Ankitsinh P. Rathod ${ }^{1}$, Tarak P. Vora ${ }^{2}$ \\ ${ }^{1} P G$ Student, Marwadi Education Foundation, Gujarat, India \\ ${ }^{2}$ Associate Professor \& Head, Civil Engineering Department, Marwadi Education Foundation, Gujarat, India
}

\begin{abstract}
Development of civil engineering is intimately connected to innovation in structural material. To full fill the requirement of advance infrastructure in India, modern technologies and innovative materials has started to makes its way. Structures with bar corrosion and other distresses requires repair, rehabilitation and retrofits for increase strength, durability and much more life span. Fiber reinforce plastic (FRP) reinforcements provides solution for such work due to its non-corrosive and non-magnetic nature also high strength and low weight ratio. Now a day FRP materials are used for internal reinforcement for RC structures worldwide.
\end{abstract}

Keywords: Fiber reinforced polymer (FRP), strength, durability, shear and flexure, fire endurance

\section{INTRODUCTION}

Primarily, FRP composites developed for the defense and aerospace industries. The development of FRP can be traced to the expanded use of composites for civil engineering after World War II. Repair, rehabilitation and up gradation of existing structures has been of great importance over some last decades. It is emerged as one of the most affordable and promising material for the corrosion and extreme weather condition. Numbers of situations where the capacity of structure need to be modified for service load, FRP composites were successfully used to resist larger design loads, repair the damages and increase durability. FRP composites provided with different fibers as Carbon, Aramid and Glass. It offers an outstanding combination of non-magnetic and non-corrosive nature.

FRP composites made up of fibers and matrix (Epoxy, vinyl ester). It is a matrix of polymeric material that is reinforced by fibers or other reinforcing material. Fiber provides strength and stiffness where as the matrix protects and transfer load between fibers. The purpose of this paper is to present the state of the art in the use of FRP bars in civil engineering. Mainly, the paper will introduce the general information about FRP bars, including properties and wide areas of application.

Table 1: Typical densities of reinforcing bars $\left(\mathrm{g} / \mathrm{cm}^{3}\right)$

\begin{tabular}{|l|l|}
\hline & Densities \\
\hline Steel & 7.90 \\
\hline GFRP & $1.25-2.10$ \\
\hline CFRP & $1.50-1.60$ \\
\hline AFRP & $1.25-1.40$ \\
\hline
\end{tabular}

Table 2: Usual tensile properties of reinforcing bars

\begin{tabular}{|l|ll|l|l|l|}
\hline Properties & Steel & $\begin{array}{l}\text { GFR } \\
\text { P }\end{array}$ & CFRP & AFRP \\
\hline $\begin{array}{l}\text { Nominal yield } \\
\text { stress( Mpa) }\end{array}$ & $\begin{array}{l}276- \\
517\end{array}$ & N/A & N/A & N/A \\
\hline $\begin{array}{l}\text { Tensile } \\
\text { strength(Mpa) }\end{array}$ & $\begin{array}{l}483- \\
690\end{array}$ & $\begin{array}{l}483- \\
1600\end{array}$ & $\begin{array}{l}600- \\
3690\end{array}$ & $1750-2540$ \\
\hline $\begin{array}{l}\text { Elastic } \\
\text { modulus(Gpa) }\end{array}$ & 200 & 3551 & $\begin{array}{l}120- \\
580\end{array}$ & $41-125$ \\
\hline $\begin{array}{l}\text { Yield strain (\%) } \\
0.14-\end{array}$ & .25 & N/A & N/A & N/A \\
\hline $\begin{array}{l}\text { Rupture Strain } \\
(\%)\end{array}$ & $6-12$ & $1.2-$ & $0.5-1.7$ & $1.9-4.4$ \\
\hline
\end{tabular}

\section{LITERATURE REVIEW}

Several authors have reported the work on use of FRP rebars for construction by different experiments for civil engineering applications.

A.F. Ashour [1] reports the tests of FRP rods embedded in concrete for shear capacity and flexural capacity. 12 concrete beams were tested with FRP bars on four point loading system. The dimensions for the test were selected as $150 \mathrm{~mm}$ width, $2100 \mathrm{~mm}$ length and the depth of beam varies with $200 \mathrm{~mm}, 250 \mathrm{~mm}$ and $300 \mathrm{~mm}$. Two different types of group created according to an amount of FRP bars and depth of beam. Failure modes of beams were observed under loading system, mainly shear and flexure.

Results conclude that flexure failure generates due to tensile rupture of bars at mid section or under the applied point load. Shear failure observed due to major diagonal cracks within beam shear span. And the extension of diagonal cracks horizontally to the place of bars generates bond failure. 


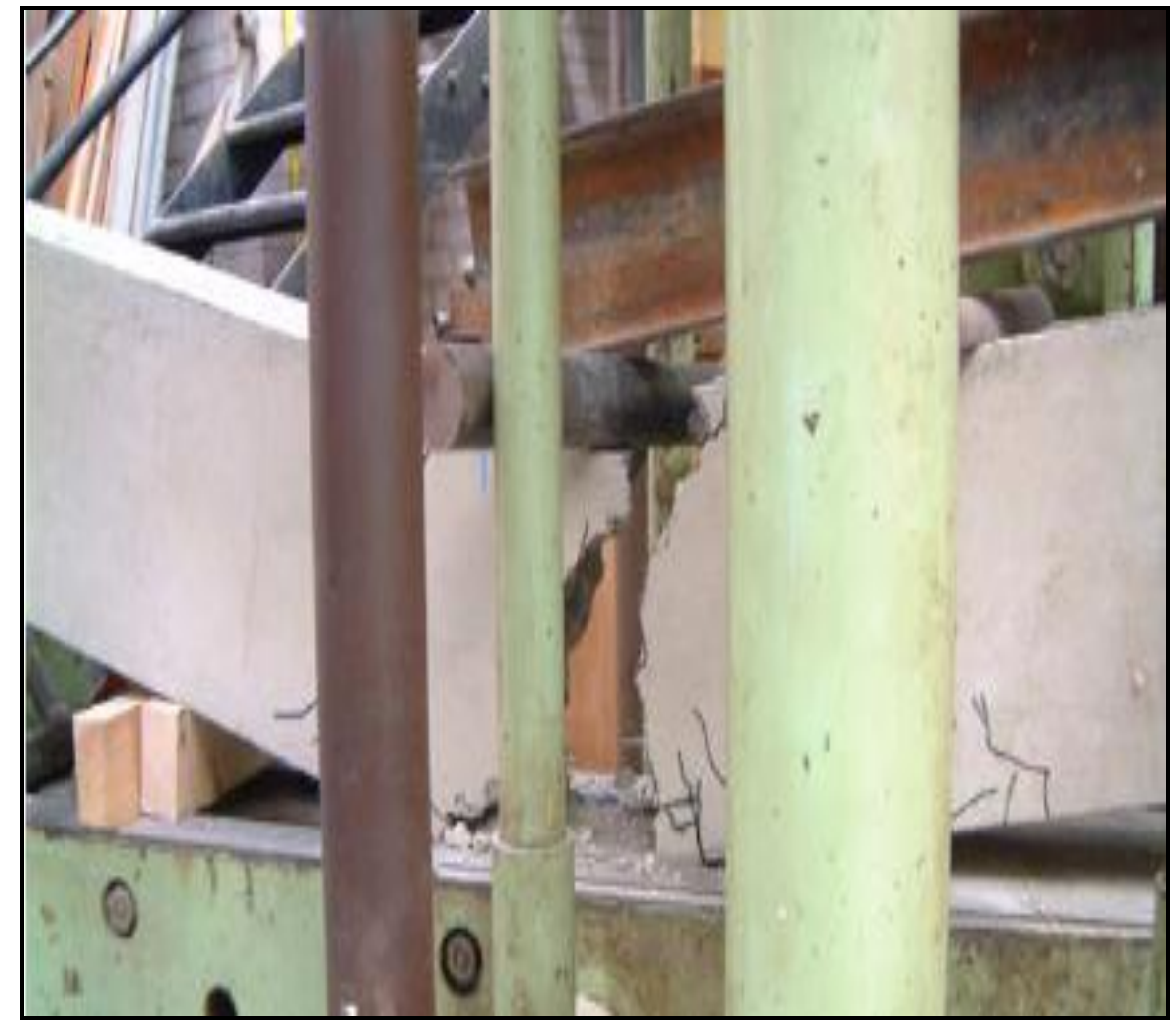

Fig.1: Flexure failure

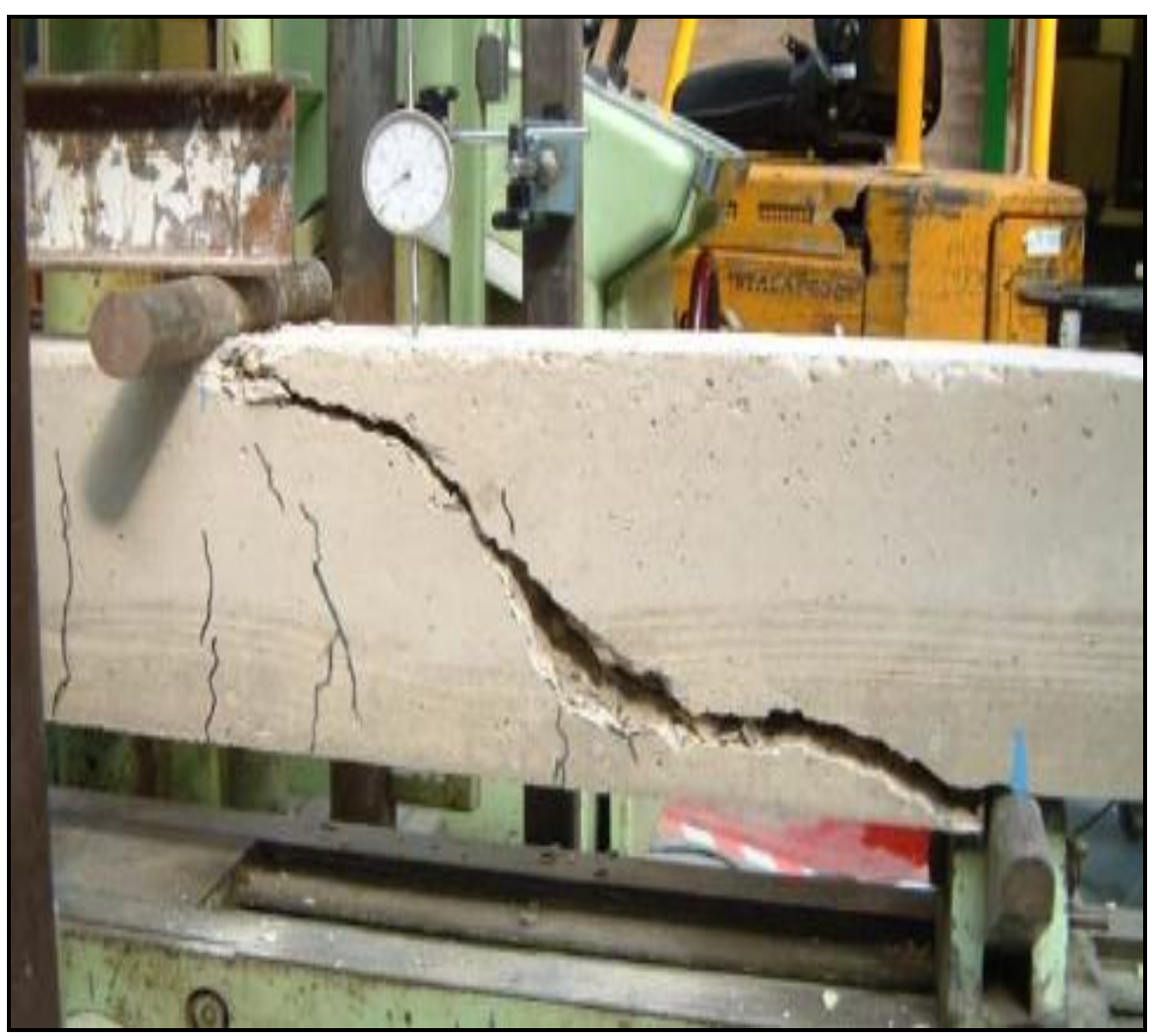

Fig.2: Shear failure

A. Masmoudi [2] and fellows observed long term deflection for RC beams reinforced with FRP bars. Total six numbers of beams were casted with steel and GFRP bars subjected to flexure capacity. All the beams were tested under four point loading system for a frequent and long time period. Results conclude that RC beams with FRP bar deflect more than steel RC beam under frequent loading but with long term period steel beams were more deflect than FRP beams. 
A. Abbasi [3] and fellows observed the behaviour of glass fiber reinforced polymer (GFRP) rebar reinforced concrete beams when exposed to fire. Researchers investigated experimental setup involved fire tests based on British Standard 476 on two full-scale GFRP rebar reinforced concrete beams. Dimensions of beam were selected as $350 \mathrm{~mm}, 400 \mathrm{~mm}$ and $4400 \mathrm{~mm}$ total length with a span length of $4250 \mathrm{~mm}$. The beams were designed and constructed as per Euro code 2 and ACI-440 guideline.

Thermo set resin GFRP rebars were used for reinforcing beam 1 and GFRP rebars with thermoplastic resin were used for reinforcing beam 2. Shear reinforcement for beam 1 was GFRP stirrups and for beam 2 steel stirrups were used.

Degradation in the flexural capacity due to fire was evaluated and compared. Also the fire resistance of the GFRP reinforced concrete $(\mathrm{RC})$ beams has been observed.

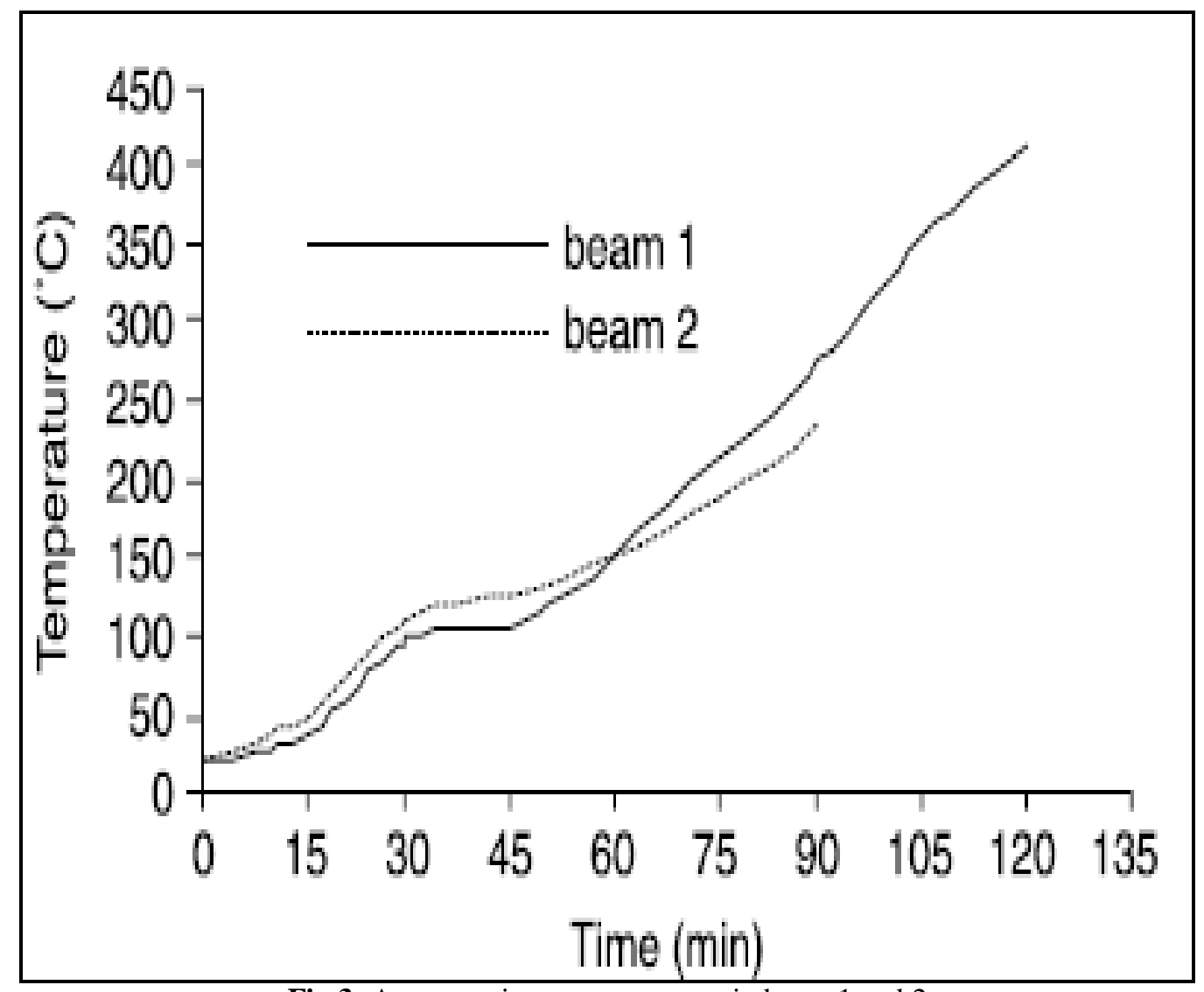

Fig.3: Average stirrups temperature in beam 1 and 2

Result indicates that the average temperature at the end of heating for bottom reinforcement in beam 1 was $462{ }^{\circ} \mathrm{C}$ and for beam 2 was $377^{\circ} \mathrm{C}$. The heating time for beam 1 was 143 min with maximum central deflection of $185 \mathrm{~mm}$ and the heating time for beam 2 was 104 min with maximum central deflection of $157.5 \mathrm{~mm}$. The fire resistance rating (load bearing capacity) for beam 1 was $128 \mathrm{~min}$ and for beam 2 was 94 min. Fire tests results show that concrete beams reinforced with GFRP rebar will meet the fire design requirements for the minimum periods of fire resistance (fire endurance) for the load.

B.Saikia [4] and fellows investigated strength and serviceability performance of $\mathrm{RC}$ beams reinforced with GFRP bars. Total 10 numbers of beams with $180 \mathrm{~mm} \mathrm{X}$ $250 \mathrm{~mm} \times 1340 \mathrm{~mm}$ dimensions were casted with two different grades of concrete M35 and M65. Design of beam selected as per limit state principles and examined strength and serviceability performance of all beams. Analytical empirical model has been proposed for the maximum Width of crack and Results predicted by the Analytical model compare with experiment data. It has been observed that comparison of both analytical and experiment shows close agreement.

C.Barris [5] and fellows present the results and discussion of an experimental programme concerning concrete beams reinforced with glass-FRP (GFRP) bars with a relatively high modulus of elasticity. Short-term flexural behaviour by varying the reinforcement ratio and the effective depth to height ratio has been observed. Code formulations and other prediction models are examined and compared with experimental results at serviceability and ultimate limit states. Researchers indicate that Current provisions predict reasonably well the behaviour up to service load. However, at the ultimate limit state, load capacity is underestimated. 
F. Micelli [6] and their fellows investigated the physical and mechanical properties of FRP rods for applying them with concrete structures. Five different types of carbon and glass fiber rods were investigated for suitability with concrete. An experimental program measuring physical and mechanical characteristics as well as durability of bars due to immersion in simulated concrete pore solution and exposure condition of an environment were studied.

Result conclude that FRP bars embedded in concrete for several years and exposed them to an alkaline environment in the presence of aggressive ions cause a loss of mechanical properties. Tensile test results showed that some samples has $100 \%$ tensile property after immersion them in to simulated concrete pore solution and after many environmental cycles. Carbon fiber property remains as it is strong against alkaline solutions.

Iman [7] and fellows observed flexure behaviour of beams reinforced with FRP and compare the results with ACI code provisions. Researchers have taken 10 specimens and casted with fix diameter of FRP bars and Length but different width and depth. Flexure behaviour of RC beam reinforced with GFRP bars, ultimate moment capacity, deflection, first crack are identified under loading. Results taken from the experimental tests have been compared with ACI 440 and they show that deflections, width of cracks and the cracks' extent are further used toward the usual RC beams. In addition, it can be said that the amount of the balanced bar provided by ACI 400 is not an exact criteria to determine the type of failure, and it is only in cases where the ratio of bars are lower than the balanced mode that ruptures occur in reinforcement area.

I.F.Kara [8] and fellows observed comparison between predefine numerical method and experiment data for $\mathrm{RC}$ beams reinforced with FRP bars. Numerical method for estimating the curvature, deflection and moment capacity of FRP reinforced $\mathrm{RC}$ beam is developed. Also the modification of mid span proposed for mid span flexural rigidity. Comparison with experiment results shows that numerical technique is accurately predict the moment capacity, curvature, deflection of FRP reinforced beam. It also concludes that increase in FRP bars slightly increase the moment capacity of over reinforced beam but greatly reduce the deflection after first cracking.

\section{DISCUSSION}

Based on various researchers, it is observed that FRP bars are preferable material and can be used for construction. All the researchers noticed FRP bars for different suitable parameters for construction. Most of the researchers noticed positive results for FRP reinforcements for the concrete structure. Also, the failure modes of structure can be noticed mainly flexure and shear. It could also be noted that the fibers are affected by some aggressive nature condition.

\section{CONCLUSION}

Based upon above literature review it could be concluded that FRP composites can be used for construction. By having the only drawback as brittle material, it can be an alternative to the conventional reinforcing material steel to have sustainable structures considering other advantages like noncorrosive, light weight and high strength. However, the material is in investigation level and extensive research is going on worldwide, where researchers have noted that two major parameter like fire resistance and shear capacity as and reinforcement require further investigation.

\section{REFERENCES}

[1]. A.F. Ashour "Flexural and shear capacities of concrete beams reinforced with GFRP bars" Elsevier. Aug 2005

[2]. Abdelmonem masmoudi, Mongi Ben Ouezdou, Jamel Bouaziz, "New parameter design of GFRP RC beams", Construction and Building Materials, Elsevier. Nov-2011

[3]. A. Abbasi, P.J. Hogg, "Fire testing of concrete beams with fiber reinforced plastic rebar", Composites part A 37, Elsevier, May 2005

[4]. Biswarup Saikia, Phanindra Kumar, Job Thomas, K.S. Nanjunda Rao, Ananth Ramaswamy, "Strength and serviceability performance of beams reinforced with GFRP bars in flexure", Construction and Building Materials, Elsevier. Sept-2006

[5]. C. Barris, L. Torres, A. Turon, M.Baena, A. Catalan, "An experimental study of the flexure behaviour of GFRP beams and comparison with prediction models", Composites structures-Elsevier, May 2009

[6]. Francesco Micelli, Antonio Nanni "Durability of FRP rods for concrete structures" Elsevier -Construction and Building Material. June 2004

[7]. Iman Chitsazan, Mohsen Kobraei, Mohd Zamin Jumaat and Payam Shafigh, "An experimental study on the flexural behaviour of FRP RC beams and a comparison of the ultimate moment capacity with ACI", Journal of Civil Engineering and Construction Technology, Dec 2010

[8]. Ilker Fatih Kara and Ashraf F. Ashour, "Flexural performance of FRP reinforced concrete beams", Composite Structures, Elsevier. Dec-2011

[9]. ACI 440 1R-06 "Guide for the Design and Construction of Structural Concrete Reinforced with FRP Bars”.

\section{BIOGRAPHIES}

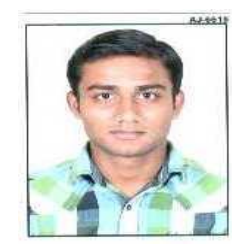

Ankitsinh Pravinsinh Rathod was born in 1992 in Kosamba, Gujarat. He receives his Bachelor of Engineering degree in Civil Engineering from the Government Engineering College, Valsad in 2013. At present he is Final year student of Master's degree in Structural engineering from Marwadi Education Foundation Group of Institutions, Gujarat Technological University.

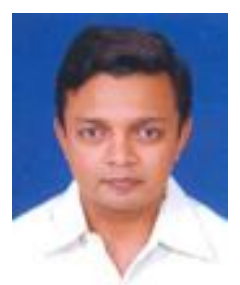

Prof. Tarak P. Vora an academician by heart with a teaching experience of thirteen years. He is pursuing his $\mathrm{PhD}$ in Civil Engineering from Gujarat Technological University. His area of interest is experimental stress analysis, FE Analysis, Structural Dynamics etc. 